\title{
Neutronic Analysis of The SMART Modular Reactor Fuel Using SRAC 2006
}

\author{
Nailatussaadah $^{1, a}$ and Irsyad ${ }^{1}$ \\ ${ }^{1}$ Bandung TRIGA 2000, Directorate of Nuclear Management Facilities, Deputy for Research and \\ Innovation Infrastructure, National Research and Innovation Agency, Jl. Tamansari No. 71, \\ Bandung, 40132, INDONESIA \\ anailatuss@yahoo.com
}

\begin{abstract}
Neutronic analysis of The SMART modular reactor fuel using SRAC 2006 has been carried out. Electrical energy is important today because the need is increasing along with the increase in human population, advanced technology and the economy. On the other hand, there are demands from the community for the clean, efficient and consistent energy. This is the reason why nuclear power plants are considered as one of the candidates for electrical energy suppliers in Indonesia in particular. This study evaluates a SMART reactor with Gadolinium as the burnable absorber material. The two kinds of fuel assembly were analyzed using the SRAC 2006 code system with the JENDL 4.0 as nuclear data library. This study aims to observe the neutronic characteristics of the fuel assembly designs according to the reference used. The results of the study show that of all types of fuel assemblies used can reach criticality at the beginning of the operating cycle and last up to 3 till 5 years when it finally reaches subcritical condition. Another parameter observed is the conversion ratio value, which from this study is in accordance with the characteristics of the conversion ratio for thermal reactors.
\end{abstract}

Keywords: SMART, JENDL 4.0, SRAC, Neutronic.

\section{Introduction}

It is fully realized that human beings are very dependent on energy, especially electrical energy. Starting from primary needs to secondary human needs must be related to electrical energy. The state through the relevant ministries in charge of the energy sector must of course have a strategy so that energy needs are always met and predict future energy needs to avoid an energy crisis. The energy needs of a country normally will always increase every year along with the increase in population, economic growth, energy prices and technological developments [1].

The world's energy sector today is mostly driven by fossil fuel power generation. To address and meet national and global requirements for clean, efficient and consistent energy, energy production is designed to meet the growing energy demands of developing countries. New and innovative nuclear reactor technology needs to be developed. One of the initiations of this technological development is the potential utilization of modular nuclear reactors. It is the reactors with smaller size [2].

One of the power reactors candidates to be built in Indonesia is the Small Modular Reactor type. This reactor has several advantages such as the investment risk is not too high, advanced safety features, the size or dimensions of the reactor are not large, and is able to produce large 
enough power in the same class as a power reactor with a size that is not too large in terms of physical appearance [3].

Then the power reactors in the SMR group have several types of designs from several countries, such as KLT40s from Russia, CAREM from Argentina, HTR-PM China or SMART which is a reactor made by South Korea. The SMART type power reactor design has been used in Saudi Arabia, where in addition to being used for electricity production, this reactor is also used for seawater desalination [3].

This study aims to analyze the neutronic characteristics of each fuel assembly used in the SMART reactor. The parameters observed were the multiplication factor, conversion ratio value, and changes in the density of important nuclides, such as U-235 and U-238. Because in this study the characteristics of the fuel assembly were observed, which did not take into account the conditions around the core such as the reflector, the resulting and representative multiplication factor value was the $k$-inf value (infinite multiplication factor). While the value of $k$ eff (effective multiplication factor) is generated from the calculation of the core which will be carried out in further research. Indirectly, this study is also used to observe the effect of the use of burnable absorber materials on fuel, where the absorber material used is Gadolinium.

This study uses a SMART reactor with a thermal power of $330 \mathrm{MW}$ and an operating cycle of 3 years for one core. The author uses the six types of fuel assemblies with specifications according to the reference. This reactor uses light water as the moderator. There are two types of fuel used, namely $\cup_{2}$ and $\cup_{2}+\mathrm{Gd}_{2} \mathrm{O}_{3}$ [2]. The results of this study will be used for the core analysis.

\section{Theoretical Background}

The Korean Atomic Energy Research Institute (KAERI) has been planning to build a smallpower modular reactor (SMR) since 2012 [4-7]. This reactor is a $330 \mathrm{MW}$ thermal integral reactor with one pressure vessel, and the main primary components such as steam generator inlet, eight steam generators, four reactor coolant pumps, assembly flow mixing header and flow skirt. Reactor safety has been improved by reducing the frequency of core breakdown to 1/10 of the old type reactor. In some conditions the reactor can be extinguished by inserting a control rod or infusing Boron [5-8].

The specification of SMART reactor can be seen in table 1.

Table 1. Specification of SMART Reactor

\begin{tabular}{clc}
\hline No & \multicolumn{1}{c}{ Parameter } & Value \\
\hline 1. & Thermal power (MW) & 330 \\
2. & Electric power (MW) & 100 \\
3. & Active core height $(\mathrm{cm})$ & 200 \\
4. & Type of fuel assembly & $17 \times 17 \mathrm{KOFA}$ \\
5. & Pin pitch (cm) & 1.2598 \\
6. & Cladding & $\mathrm{Zircaloy}^{2}$ \\
7. & Type of fuel & $\mathrm{UO}_{2}$ \\
8. & U-235 enrichment (\%) & $<5$ \\
9. & Burnable absorber & $\mathrm{Gd}_{2} \mathrm{O}_{3}$ \\
10. & Gd percentage (\%) & 8 \\
11. & Cladding of GT and IT & Zircaloy-4 $^{2}$ \\
\hline
\end{tabular}


The picture of the fuel assemblies of the SMART reactor is as follows:

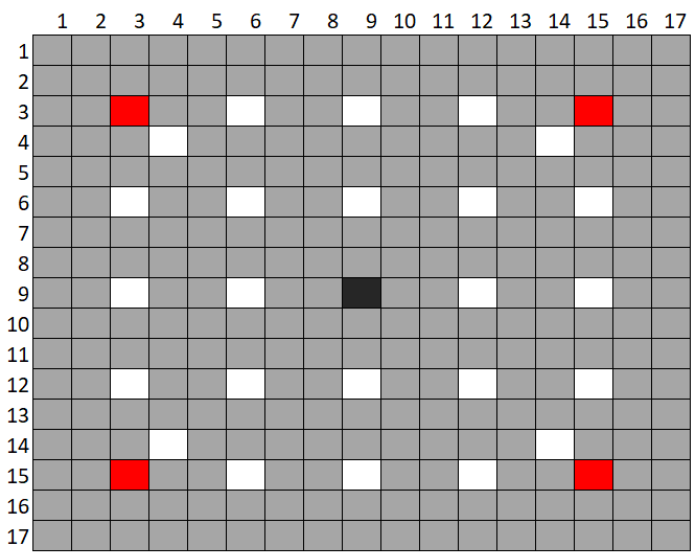

Type 1

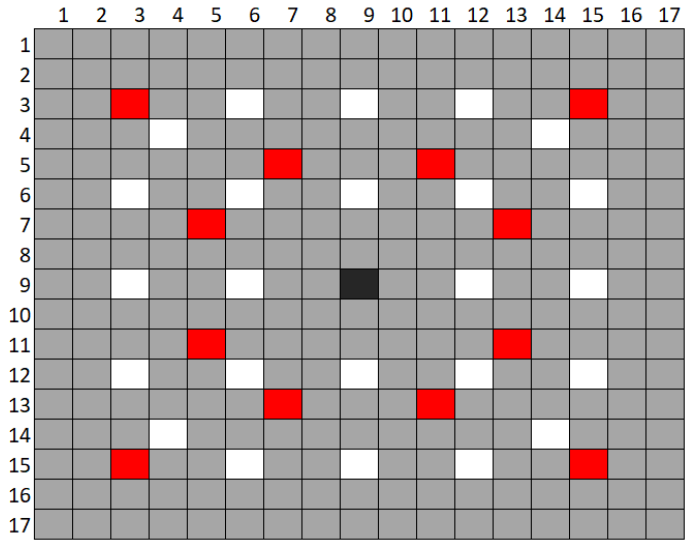

Type 3

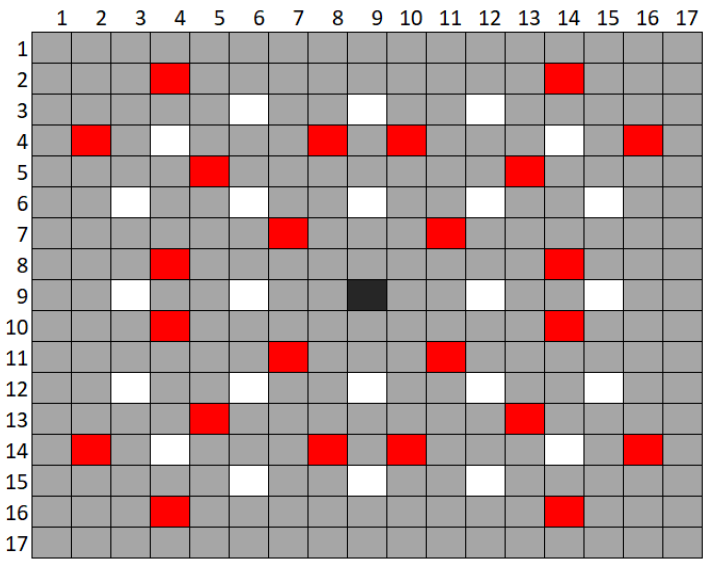

Type 6

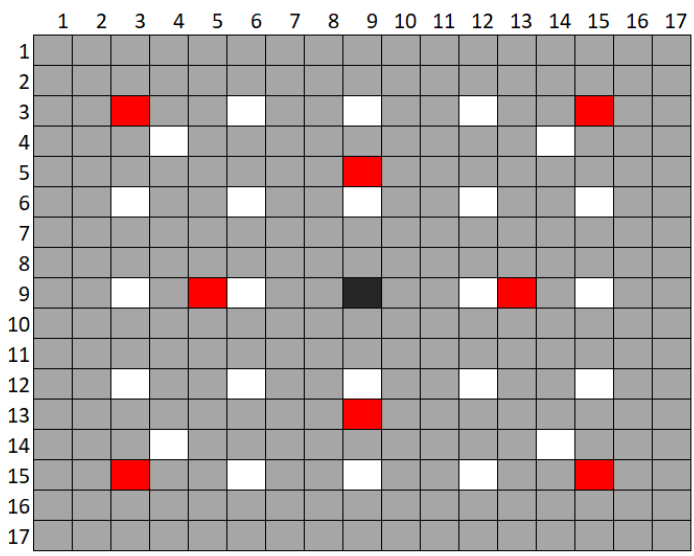

Type 2

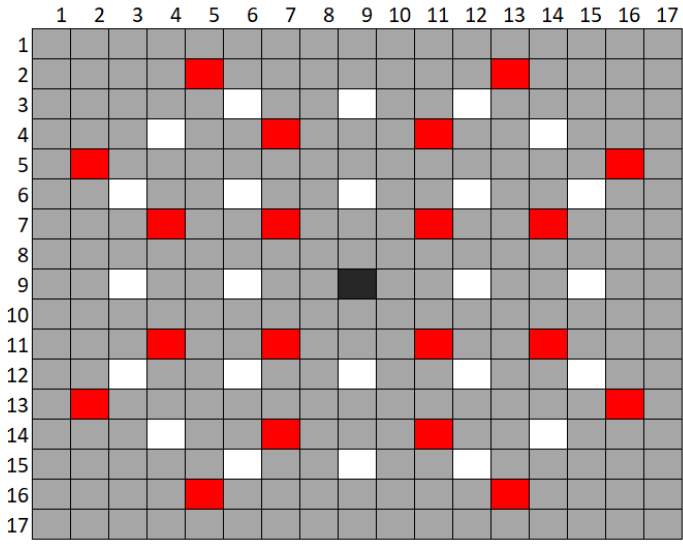

Type 5
Standar fuel rod

IFBA

Guide tube

Central thimble

Figure 1. Arrangement of IFBA rods in different assemblies [2] 
A complete description of each type of SMART type nuclear reactor fuel device is shown in table 2.

Table 2. Specification of fuel assemblies

\begin{tabular}{ccccc}
\hline Assembly & $\begin{array}{c}\mathrm{UO}_{2} \text { enrichment } \\
(\mathrm{w} / \mathrm{o})\end{array}$ & No. of standard fuel rods & No. of Gd fuel rods & $\begin{array}{c}\mathrm{Gd}_{2} \mathrm{O}_{3} \\
\text { enrichment } \\
(\mathrm{w} / \mathrm{o})\end{array}$ \\
\hline A2 & 2.82 & 256 & 8 & 8 \\
A3 & & 252 & 12 & 8 \\
B1 & 4.88 & 260 & 4 & 8 \\
B2 & & 256 & 8 & 8 \\
B5 & & 244 & 20 & 8 \\
B6 & & 240 & 24 & 8 \\
\hline
\end{tabular}

The fuel assembly type A and B differ only in the active length of the fuel rod. This will be shown in Figure 2.

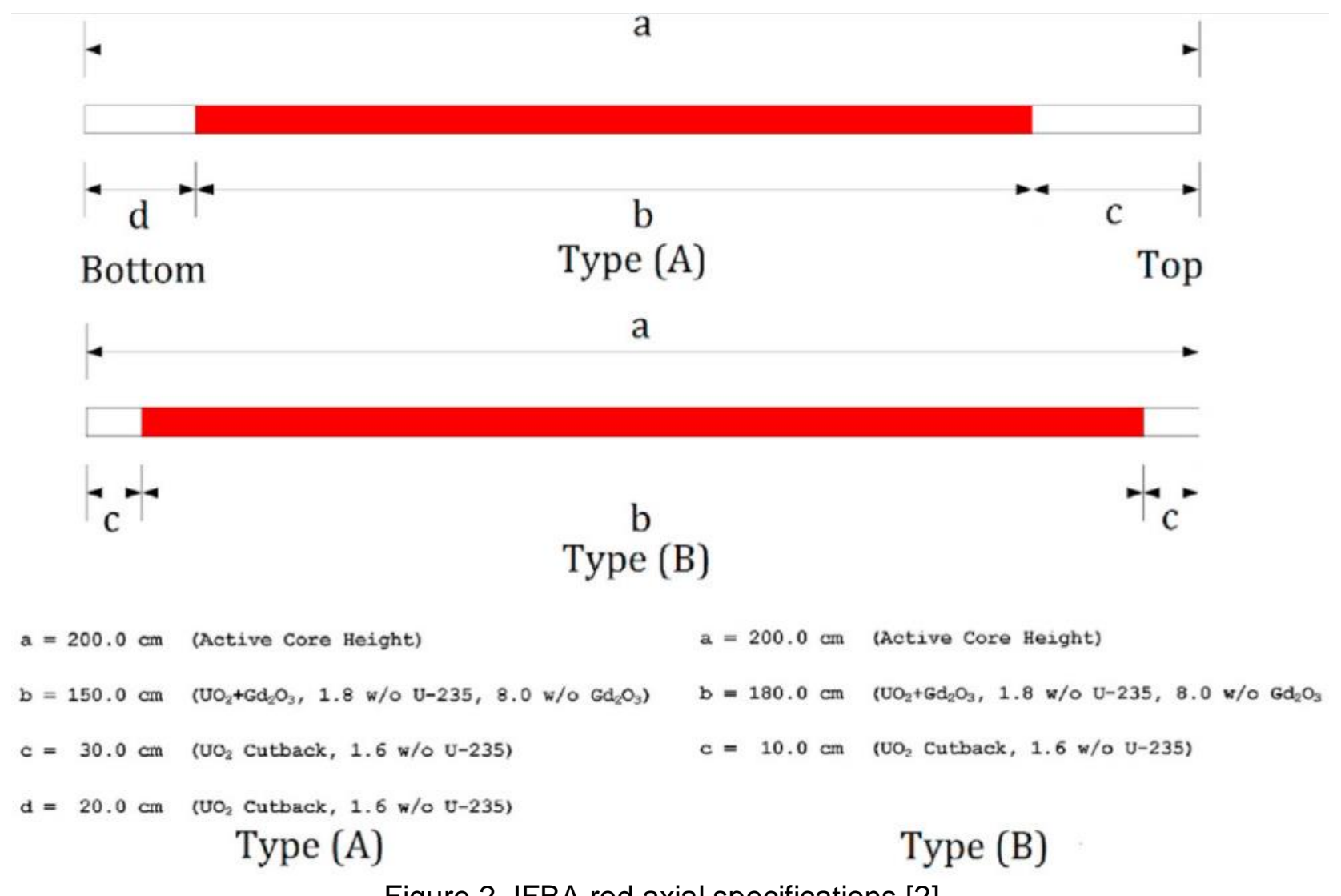

Figure 2. IFBA rod axial specifications [2]

Fuel assembly A2 is a fuel assembly with arrangement scheme and a type A for the fuel rod scheme. And so on for other types of fuel devices. 


\section{Materials and Methods}

Figure 3 shows the flowchart of this research. The first step is to determine the type of fuel used, namely $\mathrm{UO}_{2}$. Then, determine the burnable absorber material, this study used $\mathrm{Gd}_{2} \mathrm{O}_{3}$ that is integrated into the $\mathrm{UO}_{2}-\mathrm{Gd}_{2} \mathrm{O}_{3}$ fuel. The Gadolinium was used with the consideration that this material has a very high neutron cross-section so it is very suitable if it is used as an absorber material [10]. Furthermore, the cladding materials for both fuel and integrated burnable absorber materials are determined, namely Zircaloy-2 and Zircaloy-4. The next step is to determine the geometry of the fuel assembly, we used the symmetric square model.

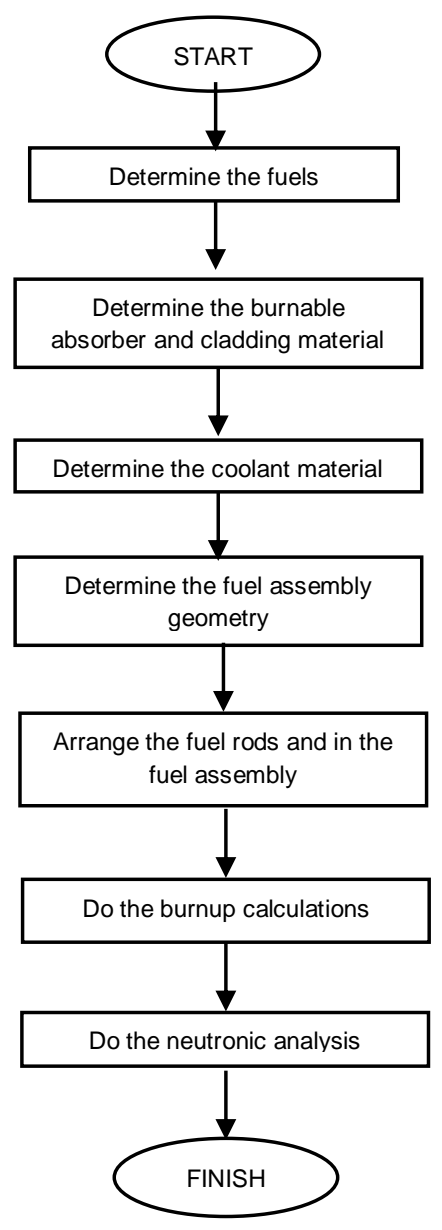

Figure 3. Flowchart of the study

The calculation of the fuel assembly's burnup in this study was carried out using the SRAC 2006 code system [11] and JENDL 4.0 as the nuclide data library [12]. This calculation is carried out at the fuel assembly level using two-dimensional homogenization in the $X$ and $Y$ directions. The calculation is also carried out with the initial assumption that the power generated from each fuel assembly is the same, resulting $330 \mathrm{MW}$ for the core thermal power. This method is commonly used at the fuel assembly level. Then, for the actual power produced by each fuel assembly, will be calculated in the core level, in which three-dimensional homogenization will be carried out. 
SRAC (Standard Reactor Analysis Code System) is a code system developed by JAERI (Japan Atomic Energy Research Institute). This code is operated in the UBUNTU system.

The fuel assembly's burnup is calculated using octane symmetric squares with a square pin model arrangement. Then the fuel assemblies are arranged in the reactor core for the calculation using the CITATION module which is part of the SRAC 2006 code system.

\section{Results and Discussion}

The first neutronic parameter to be analyzed is the criticality. This criticality value is taken for each type of the fuel assembly, that is type A2, A3, B1, B2, B5 and B6. These fuel assemblies have different number of standard fuel and IFBA (Integrated Fuel Burnable Absorber). While the Gd content in each IFBA is $8 \%$.

The infinite multiplication factor of each fuel assembly can be described as follows:

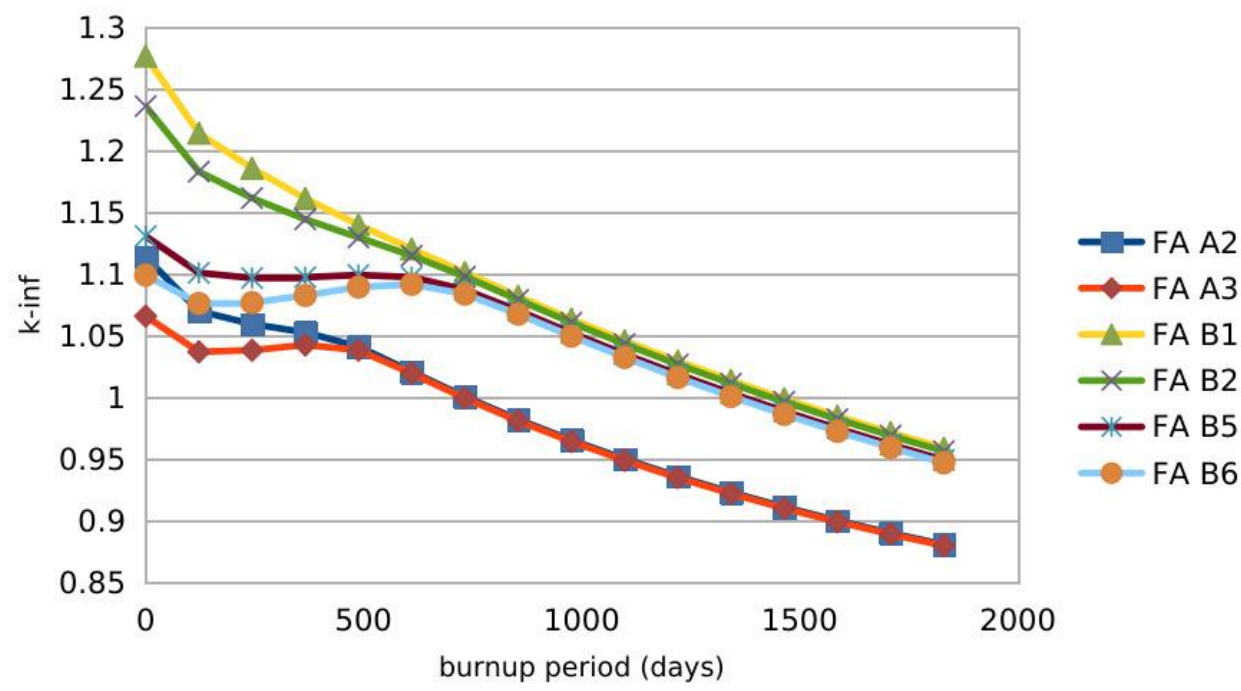

Figure 4. The $k$-infinite value to the burnup period (days)

Table 3. The $k$-infinite value

\begin{tabular}{rrrrlll}
\hline \multirow{2}{*}{ Day } & \multicolumn{5}{c}{$k$-inf } \\
\cline { 2 - 7 } & FA A2 & FA A3 & \multicolumn{1}{l}{ FA B1 } & FA B2 & FA B5 & FA B6 \\
\hline 0 & 1.11396 & 1.06596 & 1.27687 & 1.23625 & 1.13088 & 1.09925 \\
122 & 1.07007 & 1.03701 & 1.21439 & 1.18314 & 1.10111 & 1.07621 \\
244 & 1.05952 & 1.03831 & 1.18589 & 1.16168 & 1.09685 & 1.07693 \\
366 & 1.05281 & 1.04262 & 1.16138 & 1.14451 & 1.09748 & 1.08272 \\
488 & 1.04126 & 1.03836 & 1.14007 & 1.12977 & 1.09933 & 1.08953 \\
610 & 1.02092 & 1.01958 & 1.12045 & 1.11503 & 1.09755 & 1.09179 \\
732 & 1.00064 & 0.99943 & 1.1013 & 1.09802 & 1.08735 & 1.08381 \\
854 & 0.98222 & 0.98104 & 1.0821 & 1.07922 & 1.07046 & 1.06757 \\
976 & 0.96546 & 0.96432 & 1.06357 & 1.06076 & 1.05245 & 1.0497 \\
\hline
\end{tabular}




\begin{tabular}{rrrlrlr}
\hline \multirow{2}{*}{ Day } & \multicolumn{6}{c}{$k$-inf } \\
\cline { 2 - 7 } & \multicolumn{1}{c}{ FA A2 } & \multicolumn{1}{c}{ FA A3 } & FA B1 & \multicolumn{1}{c}{ FA B2 } & FA B5 & \multicolumn{1}{l}{ FA B6 } \\
\hline 1098 & 0.95014 & 0.94902 & 1.04606 & 1.0433 & 1.03517 & 1.03248 \\
1220 & 0.93606 & 0.93498 & 1.02952 & 1.02683 & 1.01885 & 1.01621 \\
1342 & 0.9231 & 0.92206 & 1.01388 & 1.01125 & 1.00343 & 1.00085 \\
1464 & 0.91117 & 0.91016 & 0.99905 & 0.99647 & 0.98883 & 0.98629 \\
1586 & 0.90018 & 0.8992 & 0.98495 & 0.98244 & 0.97497 & 0.9725 \\
1708 & 0.89007 & 0.88912 & 0.97156 & 0.96911 & 0.96183 & 0.95941 \\
1830 & 0.88076 & 0.87984 & 0.95883 & 0.95645 & 0.94935 & 0.947 \\
\hline
\end{tabular}

Figure 4 and Table 3 present the infinite multiplication factor. Figure 4 shows that at the beginning of the operating cycle, the six types of fuel assemblies have a $k$-inf value $>1.00$ which means that criticality can be achieved. The graph decreases until it reaches a subcritical condition. The subcritical condition is not the same for each type, as showed in table 3 , the FA A3 reached a subcritical condition around day 732 , FA A2 on day 854 , while the FA B1, B2, B5 and B6 lasted longer.

The critical condition of a nuclear reactor represents that the reactor can maintain a nuclear fission chain. The reaction proceeds continuously as indicated by the $k$-inf value of 1.00 .

The fuel assembly type $A$ has a smaller initial $k$-inf value than type $B$ because the enrichment in type A fuel used is only $2.82 \%$ while for type B is $4.88 \%$. The amount of U-235 as a fissile material in the fuel affects the number of fission reactions produced, which is described as the $k$-inf value.

In Figure 4 can also be seen that the decrease in the curve for fuel types A2, B1 and B2 tends to be smoother. From the beginning to the end of the cycle, the value of $k$-inf continues to decrease until it reaches a subcritical condition. It is different with fuel types A3, B5 and B6, where the curve decreases until a certain period then rises and finally decreases until it reaches a subcritical condition. This shows the effect of the amount of burnable absorber used. The fuel assembly type 1 uses only 4 IFBA rods while type 2 uses 8 IFBAs. Fuel assembly type 3, 5 and 6 use more than that, that is 12,20 and 24 IFBA rods.

The content of burnable absorber material in a fuel, will affect the number of fission reactions produced. The $k$-inf value curve for fuel assembly A3, B5 and B6, shown in Figure 4, it decreases rapidly at the beginning of the cycle. This shows the very reactive characteristics of Gd burnable absorber material. At a certain period, the $\mathrm{Gd}$ material runs out so that the k-inf value increases, then the curve returns to decline, like a standard fuel assembly.

Burnable characteristic is to extend the life of a reactor operating cycle, so that in some of the latest generation reactors, this material has been inserted in the fuel. $\mathrm{Gd}$ is one of the BA materials used in SMR.

The other parameter observed in this study is the conversion ratio. The conversion ratio is one of the benchmarks for reactor performance. The conversion ratio is the ratio of the fissile material number produced to the used/lost fissile material.

The following is the conversion ratio of the fuel assemblies used in this study. 


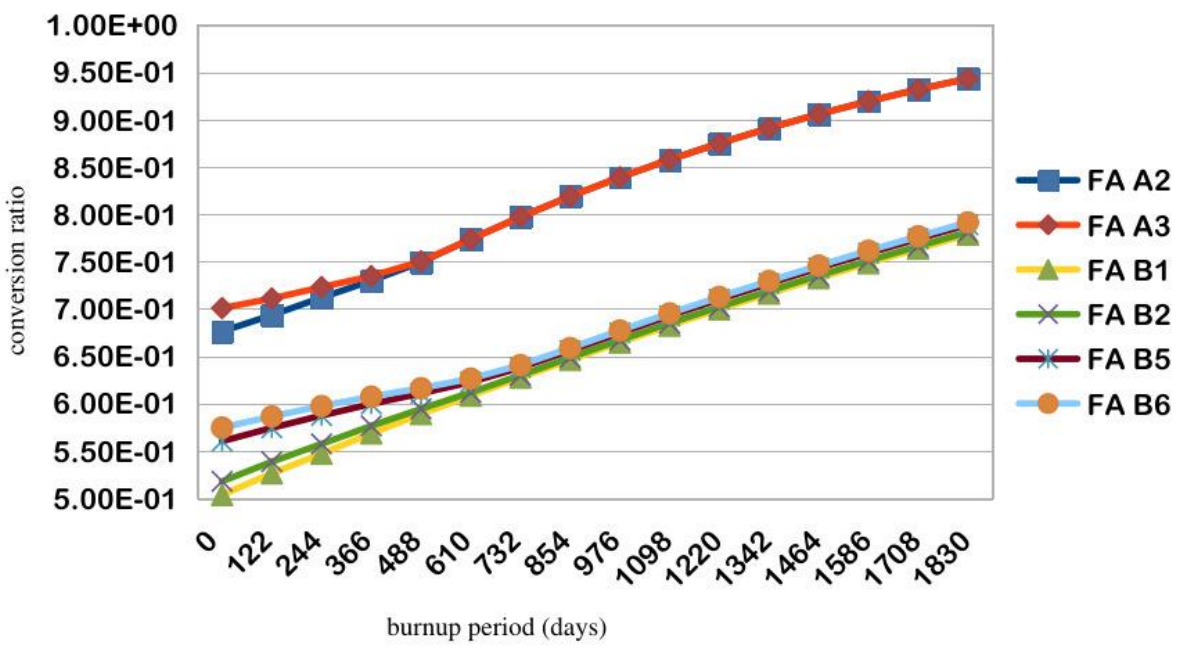

Figure 5. Conversion ratio to the burnup period (days)

The conversion average value also can be seen in Table 4 .

Table 4. Conversion ratio

\begin{tabular}{cc}
\hline $\begin{array}{c}\text { Tipe perangkat } \\
\text { bahan bakar }\end{array}$ & $\begin{array}{c}\text { Rerata rasio } \\
\text { konversi }\end{array}$ \\
\hline A2 & 0.8195 \\
A3 & 0.8232 \\
B1 & 0.6500 \\
B2 & 0.6550 \\
B5 & 0.6698 \\
B6 & 0.6748 \\
\hline
\end{tabular}

Table 4 shows that the average conversion ratio of the fuel assemblies used is below 1.000 . That means that the number of fissile material produced by this reactor is smaller than the fissile material used. This is also the characteristic of thermal reactors, the conversion ratio value $<1$. In contrast to the breeding reactor which is able to produce its own fissile material so that it can extend the reactor operating period, the conversion ratio value is $>1$.

This study also conducted an analysis of changes in the important nuclides density, such as U235 and U-238. In the reactor, these nuclides are very influential because they determine the number of fission reactions that occur in the reactor. 


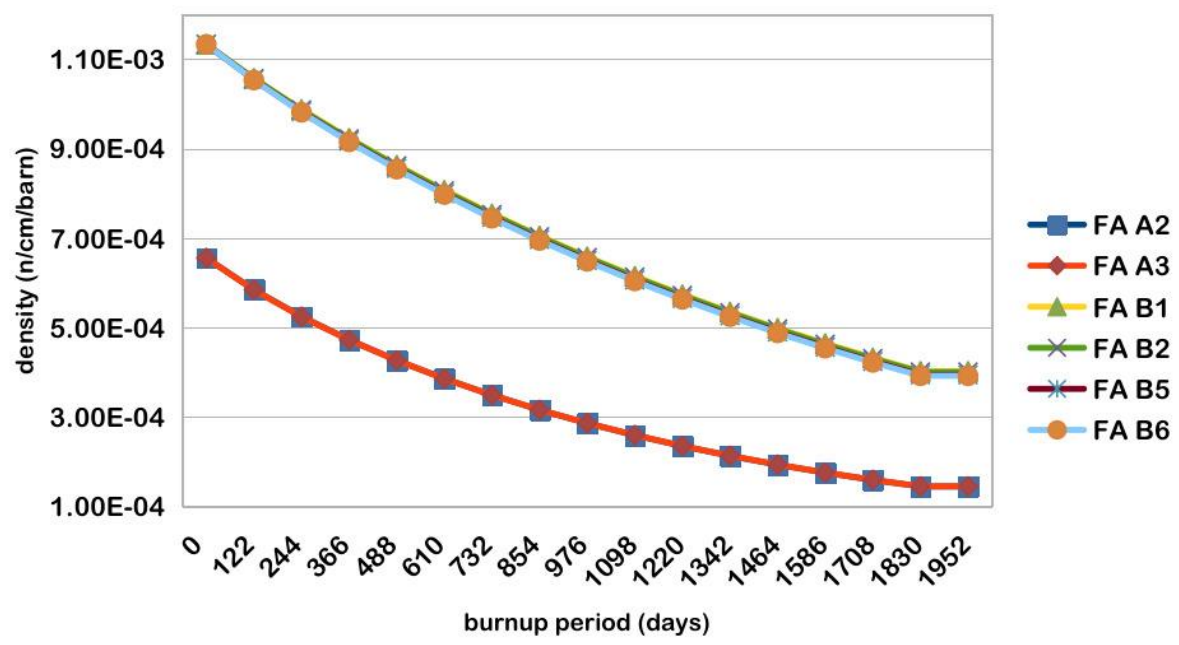

Figure 6. Changes of U-235 Nuclide Density in the operation cycle

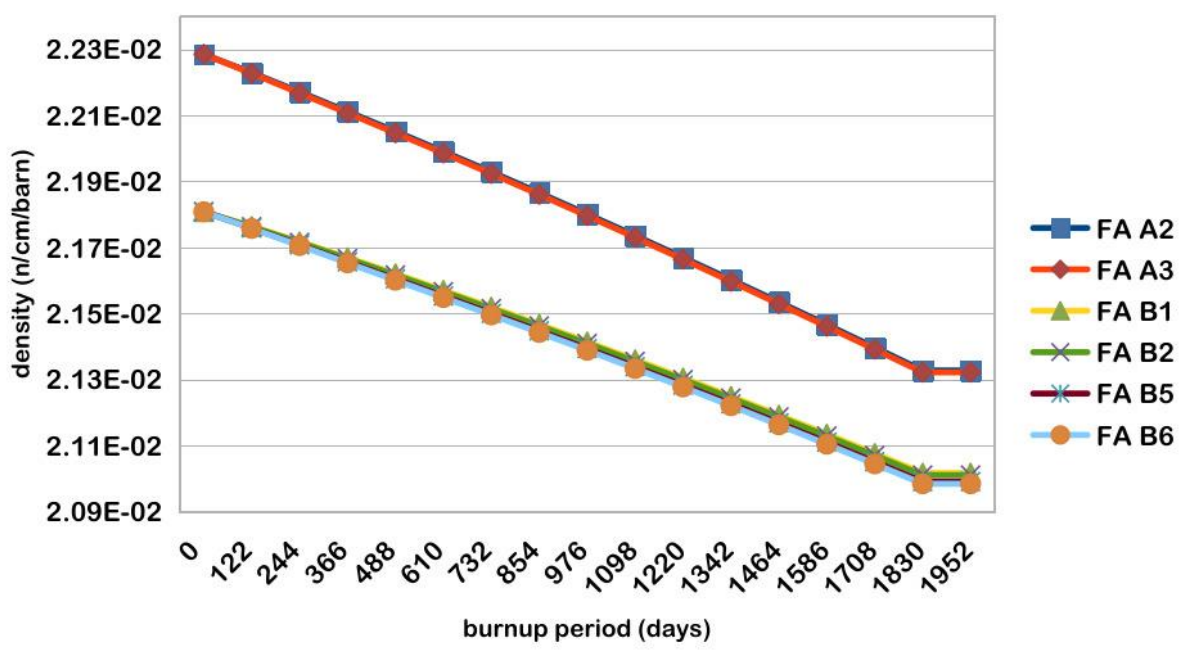

Figure 7. Changes of U-238 Nuclide Density in the operation cycle

The process of U-235 burning greatly affects the atomic density of the fuel. Figures 6 and 7 show changes in the density of the U-235 and U-238 nuclides in the fuel assemblies during the operating period. The density of U-235 and U-238 nuclides experienced a less significant reduction, in the values of $10^{-4}$ for $\mathrm{U}-235$ and $10^{-2}$ for U-238. The U-235 nuclide present in the fuel undergoes a fission reaction when it captures neutrons to produce other nuclides in the fuel. Likewise, the U-238 nuclide, which is a fertile material, will produce other elements either through fission reactions or neutron absorption. 


\section{Conclusions}

The results of the characteristic analysis of the fuel assemblies obtained from this study can be concluded as follows:

1. Fuel assembly $A 2, A 3, B 1, B 2, B 5$ and $B 6$ can reach criticality early in the operating cycle;

2. The length of the operating cycle for fuel assembly $A$ is less than 3 years while for type $B$ is close to 5 years. Seeing the character of light water reactors in general, these results are quite good, so it is hoped that the combination of these two types of fuel assembly in the core will be able to reach 3 years operating life of the reactor;

3. The conversion ratio value is less than 1.000 according to the characteristics of the thermal reactor;

4. Important nuclides such as U-235 and U-238 experienced with not too large decline so that the core remained in a critical condition for longer time;

5. Point number 4 is also affected by the number of burnable absorber contained in each fuel assembly. The greater the number of burnable absorber used, the longer the core can be maintained in a critical condition or the longer it's operating cycle.

\section{ACKNOWLEDGEMENTS}

The author would like to thank the Director of Nuclear Management Facility, Mrs. VIS Wardhani as the research coordinator, Wahid Luthfi for his knowledge sharing and my colleagues in the Reactor Division for their support to the author until the completion of this study.

\section{References}

[1] M. Carelli, G. Garrone, M. Mancini, M. Trucco, and M. Ricotti, 2010, Economics Features of Integral, Modular, Small-to-Medium Size Reactors, Progress in Nuclear Energy, volume 52, page $403-414$.

[2] A. Pourrostam, S. Talebi, and O. Safarzadeh, 2020, Core analysis of accident tolerant fuel cladding for SMART reactor under normal operation and rod ejection accident using DRAGON and PARCS, Nuclear Engineering and Technology, volume 53(3), page 741 751.

[3] R. Akbari-Jeyhouni, O.D. Rezaei, and A. Gharib, 2018, Assessment of an integral small modular reactor during rod ejection accident by using DRAGON/PARCS codes, Progress in Nuclear Energy, volume 108, page 136 - 143.

[4] Y.I. Kim, Y. Bae, Y.J. Chung, and K.K. Kim, 2015, CFD simulation for thermal mixing of a SMART flow mixing header assembly, Annals of Nuclear Energy, volume 85, page 356 370.

[5] K. Mehboob and M.S. Aljohani, 2018, Derivation of radiological source term of Korean design system-integrated modular advanced Reactor (SMART), Annals of Nuclear Energy, volume 119, page $148-161$.

[6] K.M. Kim, B.I. Lee, H.H. Cho, J.S. Park, and Y.J. Chung, 2011, Numerical study on thermohydrodynamics in the reactor internals of SMART, Nuclear Engineering Design, volume 241 , page $2536-2543$. 
[7] International Energy Agency, 2011, System-Integrated Modular Advanced Reactor (SMART, executive summary on https:// aris.iaea.org/PDF/SMART.pdf accessed on July 8 , 2021.

[8] H.K. Kim, S.H. Kim, Y.J. Chung, and H.S. Kim, 2013, Thermal-hydraulic analysis of SMART steam generator tube rupture using TASS/SMR-S code, Annals of Nuclear Energy, volume 55 , page $331-340$.

[9] S. Kamalpour, A.A. Salehi, H. Khalafi, N. Mataji-Kojouri, and G. Jahanfarnia, 2019, Impact of integral burnable absorbers on SMART reactor behaviour under normal and anomalous operational conditions, Progress of Nuclear Energy, volume 110, page $51-63$.

[10] E. Zarfianti et.al., 2017, Karakterisasi Bahan Perisai Radiasi Neutron Ultra High Molecular Weight Polyethene dengan Filler $\mathrm{Gd}_{2} \mathrm{O}_{3}$ Menggunakan Teknik Radiografi Neutron, Jurnal Ilmu Fisika, volume 9(1), page $1-6$.

[11] K. Okumura, T. Kugo, K. Kaneko and K. Tsuchihashi, 2007, SRAC2006: a Comprehensive Neutronics Calculation Code System, JAEA, Tokai.

[12] K. Shibata et.al., 2011, A New Library for Nuclear Science and Engineering, Journal of Nuclear Science and Technology, volume 48(1), page $1-30$. 